\title{
The Association between History of Body Injury during Sleep and Obstructive Sleep Apnea in REM Sleep Behavior Disorder
}

\author{
Ki-Hwan Ji, Mi-Ri Kang \\ Department of Neurology, Busan Paik Hospital, Inje University College of Medicine, Busan, Korea \\ 렘수면행동장애에서 수면 중 신체손상병력과 수면무호흡과의 연관성 \\ 지기환, 강미리 \\ 인제대학교 의과대학 부산백병원 신경과학교실
}

Received November 4, 2020

Revised November 23, 2020

Accepted November 24, 2020

Address for correspondence

Ki-Hwan Ji, MD

Department of Neurology,

Busan Paik Hospital,

Inje University

College of Medicine,

75 Bokji-ro, Busanjin-gu,

Busan 47392, Korea

Tel: +82-51-890-8613

Fax: +82-51-890-6367

E-mail: kihwanji@gmail.com
Objectives: To investigate whether a history of body injury is associated with obstructive sleep apnea (OSA) in patients with rapid eye movement (REM) sleep behavior disorder (RBD). Methods: We enrolled 56 consecutive patients with RBD, a history of dream-enacting behaviors, and polysomnographic evidence of REM sleep without atonia. Participants were asked whether they had any history of body injuries such as self-injury or bed-partner injury during sleep. The demographic characteristics and polysomnographic parameters of the groups with a history of injury $(n=34,60.7 \%)$ and without $(n=22,39.3 \%)$ were compared. The association between the history of injury and OSA was assessed. Results: OSA [apnea-hypopnea index (AHI) $\geq 5 / h$ ) was associated with a history of body injury [odds ratio $(\mathrm{OR})=6.25,95 \%$ confidence interval $(\mathrm{CI})=$ 1.64-23.84]. Additionally, the logistic regression analysis showed that insomnia severity index $(\mathrm{OR}=0.87$, $95 \% \mathrm{CI}=0.80-0.98)$ and $\mathrm{AHI}(\mathrm{OR}=1.10,95 \% \mathrm{CI}=1.02-1.18)$ were associated with history of body injury. Conclusions: Therefore, we can conclude that history of body injury is related to obstructive sleep apnea in patients with RBD.

J Sleep Med 2020;17(2):154-158

\section{서 론}

렘수면행동장애[rapid eye movement(REM) sleep behavior disorder, RBD]는 렘수면 동안 간헐적인 근 긴장의 소실(REM sleep without atonia, RSWA)이 발생하여 꿈의 내용이 행동으로 나타나(발차기, 주먹치기, 소리치기, 침대 에서 떨어지기 등) 본인이나 같이 자는 사람이 다칠 수 있는 질환으로, ${ }^{1-3}$ 렘수면을 조절하는 뇌간의 기능장애를 반영한 다. ${ }^{4}$ 국제수면질환분류 3판(International Classification of Sleep Disorders-3, ICSD-3)에 의하면 RBD의 진단을 위해 서는 병력에서 뚜렷한 꿈의 행동화로 폭력적이거나, 위험한 행동이 관찰되거나, 수면다원검사(polysomnography, PSG)

This is an Open Access article distributed under the terms of the Creative Commons Attribution Non-Commercial License (https://creativecommons.org/licenses/by-nc/4.0) which permits unrestricted non-commercial use, distribution, and reproduction in any medium, provided the original work is properly cited.
중 렘수면에서 이상행동이 확인되고, 근전도에서 RSWA가 기록되어야 한다. ${ }^{5}$ 폐쇄수면무호흡(obstructive sleep apnea, $\mathrm{OSA}$ )은 성인에게 주로 발생하며, 수면 중 상기도의 완전 또 는 부분적인 폐쇄에 의해 발생한다. OSA는 당뇨병, 고혈압, 부정맥, 심혈관 및 뇌혈관질환의 위험인자로, ${ }^{6}$ 문헌에 따라 서는 RBD 환자의 약 61 89\%까지도 OSA를 동반한다고 보 고된 바 있는데, 노화(aging)와 남성이라는 공통된 위험요인 을 공유하기 때문으로 사료된다. ${ }^{7.8} \mathrm{OSA}$ 환자에서 수면 중 무 호흡에 의한 잦은 각성으로 $\mathrm{RBD}$ 와 비슷한 행동을 보일 수 있어 감별진단이 필요함은 보고된 바 있다. ${ }^{9}$ 따라서 OSA 환 자에서 수면 중 호흡 사건에 의한 각성을 통해 $\mathrm{RBD}$ 증상과 비슷한 행동이 나타나면, OSA를 동반하지 않은 경우에 비해, $\mathrm{RBD}$ 환자 자신 또는 배우자에게 신체 손상의 병력이 있을 가능성이 더 크다. 본 연구는 $\mathrm{PSG}$ 를 통해 $\mathrm{RBD}$ 로 진단받은 환자들을 대상으로 수면 중 신체손상병력과 폐쇄수면무호 
흡과의 연관성에 대해 규명하고자 하였다.

\section{방 법}

\section{대 상}

2012년 1월 2017년 7월까지 사건수면을 주소로 내원하여 뚜렷한 꿈의 행동화 병력이 있어 수면다원검사를 시행한 환 자 중 $\mathrm{RBD}$ 로 진단받은 환자를 대상으로 하였다. $\mathrm{RBD}$ 의 진 단은 ICSD-3를 따랐다. ${ }^{5}$ 모든 대상은 한 대학병원에서 진료, 진단 및 검사를 시행하였다. 제외기준은 1) 뇌전증을 진단 받 았거나 치료 중인 자, 2) 정신과 질환이 의심되거나 정신질환 의 과거력이 있는 자, 또는 치료 중인 자, 3) 두부 외상이나 뇌졸중의 과거력이 있는 경우로 하였다. 또한 사건수면 발생 전후로 수면이나 각성상태 등에 영향을 줄 수 있는 약물을 복용한 경우도 제외하였다. 본 연구는 부산백병원 윤리심의 위원회의 승인을 받았다(IRB No. 17-0108).

\section{설문지}

설문지는 수면 클리닉에 처음 방문한 날 작성되었다. 모든 환자에게 ‘수면 중 꿈꾸는 행동으로 자신의 신체를 다쳤거나 잠자리를 같이 하는 배우자를 다치게 한적이 있는지' 여부를 조사하였다. 환자나 배우자가 통증을 느끼고 깨어난 후, 그 사실을 명확히 기억하고 있는 경우로 한정하였고, 가벼운 신 체접촉 등의 사건은 제외하였다. 엡워스졸음척도(Epworth Sleepiness Scale, ESS)는 주간 졸림증(daytime sleepiness) 의 척도로, 일상에서 접할 수 있는 8가지 상황에서 잠이 들 수 있는 가능성을 0 (절대 졸지 않음)에서 3(졸 것 같음)으로 평가하며 0 24점의 범위를 가진다. 점수가 클수록 졸림증이 심하고, 10점 이상이면 과도한 주간졸림이 있음을 의미한 다. ${ }^{10}$ 벡우울척도(Beck Depression Inventory, BDI)는 지난 2주간의 우울함정도를 측정하는 21 가지 항목으로 구성되며 0 63점의 범위를 가진다. 점수가 클수록 우울함을 뜻한다. ${ }^{11}$ 불면증심각성척도(Insomnia Severity Index, ISI)는 지난 2주 간 불면증의 심각도를 보여주는 7가지 항목으로 구성되며, 점수가 높을 수록 심한 불면증상을 의미한다. ${ }^{2}$

\section{수면다원검사}

수면다원검사는 RemLogic(Embla System, Denver, CO, $\mathrm{USA}$ )으로 시행하였다. 수면의 단계 및 각성의 판정은 뇌파 (C3-A2, C4-A1, O1-A2, O2-A1), 안전도, 턱근전도(chin $\mathrm{EMG}$ 로 하였고, 호흡량은 열전대(oronasal thermistor)와 비 압력감지기(nasal pressure transducer)로 측정하였다. 흥곽 및 복부에 장착한 호흡 유도계수 체적 기록계(respiratory inductance plethysmography)를 이용하여 호흡운동을 측정 하였고, 그 외 산소포화도(finger pulse oximetry) 및 체위 센 서, 심전도(modified V2 lead)를 측정하였다. 근전도는 턱과 양쪽 앞정강근(tibialis anterior muscle)에서 측정하였다. 수 면과 호흡 상태 평가는 이전의 보고를 따랐다. 무호흡(apnea) 은 10 초 이상 호흡이 멈추며, 비강의 온도, 압력센서를 통해 공기흐름이 $90 \%$ 이상 감소하는 상태를, 저호흡(hypopnea) 은 압력센서에 공기흐름이 10 초 이상, $30 \%$ 이상 감소를 보 이면서 산소포화도가 $4 \%$ 이상 떨어지거나 각성을 보일 때 이다. OSA는 무호흡-저호흡지수(apnea-hypopnea index, $\mathrm{AHI}$ 가 시간당 5 회 이상인 경우로 정의했다. 근전도에서 RSWA의 진단은 2007년 미국 수면학회 수면판독기준을 따 랐다. ${ }^{13}$ 총 RSWA시간을 총 REM 수면 시간 중 비율로 계산 하였고, RSWA를 긴장성(tonic)과 위상성(phasic)으로 구분 하였다. 한 에포크를 30초로 하고, 3 초씩의 미니에포크(mini epoch)를 지정하였다. 기존 수면시 근전도 소견보다 4배 이 상 진폭이 증가한 근전도의 근긴장이 한 에포크에서 $50 \%$ 이 상 연속적으로 증가한 경우 긴장성으로 정의하였다. 5 개 이 상의 미니에포크에서 비연속적으로 0.1 5초간 지속하는 4배 이상의 진폭이 증가한 근전도상의 근긴장이 관찰된 경우 위 상성으로 정의하였다.

\section{통계 분석}

두 군간의 비교를 위하여 연속형 변수는 정규성을 확인한 후, 정규성을 따르는 경우는 독립표본 $\mathrm{t}$-검정(independent t-test)을, 정규성을 따르지 않는 경우는 맨-휘트니 $U$ 검정 (Mann-Whitney U test)을 실시하였다. 비연속형 변수의 경 우 카이제곱검정(chi-square test)을 실시하였다. RBD군을 신체손상의 기왕력 여부에 따라 나누어 일반적 특성과 수면 다원검사 결과를 비교하였다. 신체손상 병력과 $\mathrm{OSA}(\mathrm{AHI} \geq$ $5 / \mathrm{h}$ )와의 연관성을 확인하기 위해 카이제곱검정을 시행하였 고, 병력에 따른 무호흡의 교차비를 구하였다. 군간 비교 시 유의미한 결과를 보인 변수들을 이용하여, 신체손상과 관련 된 요인을 확인하기 위하여 로지스틱 회귀분석을 실시하였 다. 변수들을 보정하여 유의미한 변수를 찾고자 다변량 로지 스틱 회귀분석을 시행하였다. 분석은 STATA 14.0(Stata Corp, College Station, TX, USA)를 이용하였고, 양측검정으로 유 의수준은 $p$ 값이 0.05 미만으로 하였다.

\section{결 과}

총 56명의 연구대상자 평균 연령은 $66.1 \pm 10.1$ 세이고, 남 성은 34 명 $(60.7 \%)$ 였다. 특발성 $\mathrm{RBD}$ 는 48 명, 이차성 $\mathrm{RBD}$ 는 
Table 1. Baseline demographic features in subjects with RBD according to injury history

\begin{tabular}{lccc}
\hline \multicolumn{1}{c}{ Variable } & $\begin{array}{c}\text { Absence of } \\
\text { injury history } \\
(\mathrm{n}=22)\end{array}$ & $\begin{array}{c}\text { Presence of } \\
\text { injury history } \\
(\mathrm{n}=34)\end{array}$ & $p$ \\
\hline Age (years) & $62.4 \pm 11.1$ & $68.5 \pm 8.8$ & 0.027 \\
Female (\%) & $11(50)$ & $11(32.4)$ & 0.298 \\
BMI & $23.7 \pm 2.7$ & $23.4 \pm 2.4$ & 0.571 \\
ESS* & $7.5 \pm 6.0$ & $7.1 \pm 5.7$ & 0.713 \\
BDI & $19.0 \pm 10.6$ & $13.2 \pm 9.1$ & 0.043 \\
ISI & $14.9 \pm 7.7$ & $9.9 \pm 6.6$ & 0.017 \\
Time to diagnosis & $2.4 \pm 0.6$ & $3.8 \pm 0.8$ & 0.236 \\
(years)* & & & \\
\hline
\end{tabular}

Values are presented as mean \pm standard deviation, n (\%). *MannWhitney U test. REM: rapid eyeball movement, RBD: REM sleep behavior disorder, BMI: body mass index, ESS: Epworth Sleepiness Scale, BDI: Beck Depression Inventory, ISI: Insomnia Severity Index

8명(다계통위축증 3명, 파킨슨병 5명)이었다. 평균 체질량지 수는 $23.5 \pm 2.5$, 엡워스졸음척도는 $7.3 \pm 5.8$, 벡우울척도는 $15.5 \pm 10.0$, 불면증심각성척도는 $11.9 \pm 7.4$ 였다. 평균 $\mathrm{AHI}$ 는 $18.9 \pm 17.4$ 였고, 호흡불편지수(respiratory disturbance index)는 20.2 \pm 17.6 였다. 42명(75.0\%)이 OSA(AHI $\geq 5$ )였다. 신체손상의 과거력은 34 명 $(60.7 \%)$ 에서 있었고, 이중 23명 $(67.6 \%)$ 가 남성이었다.

신체손상의 과거력에 따라 두 군으로 나누어 비교하였고, 결과는 표로 제시하였다(Table 1, 2). 신체손상의 과거력이 있는 군의 연령이 높았으며, 벡우울척도와 불면증심각성척 도는 낮았다. 신체손상의 과거력이 있는 군에서 OSA를 동반 한 경우가 30 명(71.4\%)인 반면, 과거력이 없는 군에서는 12명 (28.6\%)이었다. 신체손상의 과거력이 있을 때 OSA를 동반 할 교차비(odds ratio, OR)는 6.25[95\% confidence interval (CI), 1.64 23.84]였다.

신체손상의 과거력에 따른 OSA와의 관련 요인을 확인하 기 위하여 로지스틱 회귀 분석을 실시하였다. 신체손상의 과 거력 유무에 따른 군간 비교에서 통계적 유의성을 보인 연 령, 벡우울척도, 불면증심각성척도, $\mathrm{AHI}$ 와 유의한 차이를 보 이지는 않았지만 성별, 체질량지수, 엡워스졸음척도를 공변 량으로 하여 분석하였다. $\mathrm{AHI}(\mathrm{OR}=1.10,95 \% \mathrm{CI}=1.02$ 1.18) 와 불면증심각성척도 $(\mathrm{OR}=0.87,95 \% \mathrm{CI}=0.80 \sim 0.98)$ 가 신체 손상의 과거력에 유의한 영향을 주는 요인이었다(Table 3).

\section{고 찰}

본 연구는 RBD 환자에게서 신체손상의 병력과 수면무호
Table 2. Polysomnographic parameters in subjects with RBD according to injury history

\begin{tabular}{|c|c|c|c|}
\hline Variable & $\begin{array}{l}\text { Absence of injury } \\
\text { history }(n=22)\end{array}$ & $\begin{array}{l}\text { Presence of injury } \\
\text { history }(\mathrm{n}=34)\end{array}$ & $p$ \\
\hline TIB (min)* & $475.9(465.0-517.0)$ & $452.4(441.0-494.2)$ & 0.036 \\
\hline $\operatorname{TST}(\min )^{*}$ & $404.8(358.0-423.0)$ & $387.2(340.5-423.4)$ & 0.169 \\
\hline $\mathrm{SL}(\min )^{*}$ & $10.5(3.5-18.0)$ & $11.5(3.0-23.5)$ & 0.860 \\
\hline REML (min)* & $87.5(61.5-109.0)$ & $71.0(46.5-101.8)$ & 0.235 \\
\hline N1 (\%)* & $22.2 \pm 13.2$ & $37.89 \pm 24.9$ & 0.002 \\
\hline N2 (\%) & $57.8 \pm 12.8$ & $44.9 \pm 16.0$ & 0.002 \\
\hline N3 (\%)* & $0.3 \pm 1.0$ & $0.1 \pm 0.3$ & 0.436 \\
\hline $\operatorname{REM}(\%)^{*}$ & $19.7(14.8-25.7)$ & $19.6(17.1-25.4)$ & 0.633 \\
\hline SE $(\%)^{*}$ & $79.8(71.8-88.7)$ & $81.1(74.9-87.7)$ & 0.880 \\
\hline WASO (min)* & $75.7(50.0-115.0)$ & $67.3(49.6-103.2)$ & 0.621 \\
\hline AHI $(/ \mathrm{hr})^{*}$ & $10.2(2.3-14.0)$ & $16.9(10.6-39.9)$ & 0.002 \\
\hline $\mathrm{RDI}(/ \mathrm{hr})^{*}$ & $10.9(3.3-16.8)$ & $18.5(11.6-42.8)$ & 0.006 \\
\hline $\mathrm{AI}(/ \mathrm{hr})^{*}$ & $19.4(11.2-22.1)$ & $21.2(15.9-29.0)$ & 0.151 \\
\hline $\operatorname{PLMI}(/ \mathrm{hr})^{*}$ & $5.8(0.0-33.6)$ & $5.8(0.0-34.0)$ & 0.752 \\
\hline Phasic REM* & $11.0(7.7-45.5)$ & $17.0(7.3-33.3)$ & 0.840 \\
\hline Tonic REM* & $6.6(2.8-11.0)$ & $9.9(3.9-25.2)$ & 0.185 \\
\hline Sleep apnea & & & 0.005 \\
\hline $\mathrm{AHI} \leq 5 / \mathrm{h}$ & $10(45.5)$ & $4(11.8)$ & \\
\hline $\mathrm{AHI} \geq 5 / \mathrm{h}$ & $12(54.5)$ & $30(88.2)$ & \\
\hline Mild & $7(58.3)$ & $11(36.7)$ & \\
\hline Moderate & $4(33.3)$ & $7(23.3)$ & \\
\hline Severe & $1(8.3)$ & $12(40)$ & \\
\hline
\end{tabular}

Values are presented as mean \pm standard deviation, $\mathrm{n}(\%)$, or median (interquartile range). Mild: $5 \leq \mathrm{AHI}<15$, moderate: $15 \leq \mathrm{AHI}<30$, severe: $\mathrm{AHI} \geq 30$. *Mann-Whitney $\mathrm{U}$ test. REM: rapid eyeball movement, RBD: REM sleep behavior disorder, TIB: time in bed, TST: total sleep time, SL: sleep latency, REML: REM latency, SE: sleep efficiency, WASO: waking after sleep onset, AHI: apnea-hypopnea index, RDI: respiratory disturbance index, AI: arousal index, PLMI: periodic limb movement index

흡의 연관성을 탐색하고자 하였다. 신체손상의 병력이 있는 경우 폐쇄수면무호흡을 동반할 교차비는 6.25였고, 신체손상 의 병력과 관련된 요소는 낮은 불면증심각성척도( $\mathrm{OR}=0.87)$ 와 무호흡-저호흡지수 $(\mathrm{OR}=1.10)$ 였다

$\mathrm{RBD}$ 환자의 수면 중 행동은 매우 복잡하고 다양하다. 팔 다리를 뻗거나, 잡거나, 후려치거나, 손이나 다리로 치거나, 일어나 앉거나, 침대에서 뛰기도 한다. ${ }^{14}$ 복잡하고 다양한 임 상양상 중에 폭력적인 꿈의 행동화는 특히 신체손상의 위험 을 높인다. Olson 등은 93명의 RBD 환자를 신체손상 병력에 따라 분류했을 때 본인이 다친 경우가 30 명(32\%), 배우자를 공격한 경우가 53명 $(64 \%)$ 으로, 그중 13명의 배우자가 다쳤다 고 보고했다. ${ }^{8}$ Iranzo 등은 불쾌한 꿈과 수면 중 이상행동을 호소하나 $\mathrm{PSG}$ 를 통해 $\mathrm{RBD}$ 가 배제된 16 명의 OSA 환자가 
Table 3. Multivariable logistic regression for contributing factors of having history of injury during sleep in subjects with RBD

\begin{tabular}{ccccccc}
\hline Variable & $\beta$ & Unadjusted OR (95\% CI) & $p$ & $\beta$ & Adjusted OR (95\% CI) & $p$ \\
\hline ISI & -0.100 & $0.90(0.83-0.99)$ & 0.023 & -0.1210 & $0.87(0.80-0.98)$ & 0.023 \\
AHI & 0.070 & $1.07(1.02-1.13)$ & 0.008 & 0.0930 & $1.10(1.02-1.18)$ & 0.013 \\
Age & 0.066 & $1.07(1.01-1.14)$ & 0.025 & & & \\
\hline
\end{tabular}

Adjusted with age, sex, Beck Depression Index, Epworth Sleepiness Scale, body mass index. RBD: rapid eye movement sleep behavior disorder, OR: odds ratio, CI: confidence interval, ISI: Insomnia Severity Index, AHI: apnea-hypopnea index

수면 중 $68 \%$ 에서 주먹질, $25 \%$ 에서 침대에서 떨어짐, $25 \%$ 에 서 발길질, $12.5 \%$ 에서 잠자리 배우자를 공격하는 행동을 보 였다고 보고했다. ${ }^{9}$ 즉 상당수의 수면 중 이상행동을 보이는 $\mathrm{OSA}$ 환자가 신체손상의 위험에 노출되어 있음을 의미한다. 중증 OSA 환자가 RBD와 비슷한 행동을 보일 수 있고, 이러 한 행동은 모두 호흡장애와 연관된 각성과 더불어 발생하였 다. ${ }^{9} \mathrm{RBD}$ 환자가 $\mathrm{OSA}$ 를 동반질환으로 가지고 있는 경우, 렘 수면 중에는 RSWA로 인한 꿈의 행동화가 나타나고, 비렘 수면 또는 렘수면시에도 호흡장애에 의한 각성에 의해 이상 행동이 나타날 수 있다. 따라서 RBD에 OSA가 동반되면 신 체 손상의 위험이 더 높다. 우리의 연구 결과는 이러한 가설 을 지지한다. 하지만 수면다원검사에서 렘수면 중 뚜렷한 꿈 의 행동화를 나타냈던 경우는 총 17명(30.3\%)이었고, 호흡 장애에 의한 각성으로 꿈의 행동화가 확인된 경우는 없었다. 이는 $\mathrm{RBD}$ 환자에게 $\mathrm{OSA}$ 가 동반된 경우 호흡장애와 연관된 각성 이외 다른 기전이 꿈의 행동화나 이상행동에 작용했을 가능성을 시사한다. 신체손상병력은 중증의 OSA에만 국한 되지 않고, 경증부터 중증의 OSA에 걸쳐서 분포하였다. 최근 OSA 환자의 악몽에 대한 연구는 중증의 OSA 환자에서 보 다는 오히려 경증의 OSA에서 꿈의 회상이 많고, 감정적, 주 로 적대적이거나 폭력적인 악몽의 경험이 많다고 한다. ${ }^{15}$ 이 는 중증 OSA의 렘수면 억제 효과에 의한 것으로 보인다. ${ }^{16}$ $\mathrm{RBD}$ 와 $\mathrm{OSA}$ 에서 보이는 뇌의 기능적 변화에 의한 영향도 잠재적 요인으로 고려해 볼 수 있다. ${ }^{17,18} \mathrm{RBD}$ 와 $\mathrm{OSA}$ 를 동시 이환한 경우 RBD에 의한 꿈의 행동화와 OSA에 의한 호흡 관련 잦은 각성, 그 외 여러 요인이 작용하여 신체손상의 발 생위험이 높다고 추정할 수 있다.

$\mathrm{RBD}$ 와 OSA가 다른 병태생리학적 기전을 가졌고, 그 임상 적인 결과가 다르기 때문에 그 둘을 구별하는 것도 중요하지 만, 역으로 $\mathrm{RBD}$ 와 $\mathrm{OSA}$ 가 동시에 이환된 상태에서는 각각의 질병의 이해에 기반하는 통합적인 치료가 필요하다. 양압치 료없이 $\mathrm{RBD}$ 의 일차 치료 약제로 선택되는 클로나제팜(clonazepam)을 복용하면 OSA를 악화시킬 수 있다. ${ }^{19}$ 양압치료만 사용하면 무호흡에 의한 이상행동을 줄이고, 일부 $\mathrm{RBD}$ 증상 을 완화 시킬 수도 있지만, 이 역시 제한적인 치료이다. ${ }^{9}$ 따라 서 $\mathrm{RBD}$ 와 $\mathrm{OSA}$ 의 동시 이환 여부를 최대한 빨리 진단하고
함께 치료하는 것이 중요하다. 하지만 OSA 환자에게 보이는 전형적인 특징과는 다르게 $\mathrm{RBD}$ 와 $\mathrm{OSA}$ 를 동반질환으로 가 진 경우, 전형적인 OSA 환자에 비해 체중이 덜 나가고, 코골 이가 덜한 경향이 있다. ${ }^{20}$ 따라서 $\mathrm{RBD}$ 증상을 보이는 환자 에게서 OSA의 동반 이환 여부를 임상적으로만 구분하기는 어려우며, RBD의 진단 뿐만 아니라, 동반되어 있을 수 있는 $\mathrm{OSA}$ 의 확인을 위해서도 수면다원검사를 시행해야 할 것이다.

$\mathrm{RBD}$ 환자는 삶의 질 저하를 보이며, 이러한 저하는 우울 증과 그와 관련된 불면증상에 기인하는 것으로 보인다. ${ }^{21}$ 본 연구에서는 신체 손상의 병력은 불면증심각성척도와 음의 관계를 보였다. 또한 신체 손상의 병력이 있는 군에서 벡우 울척도 점수가 유의하게 낮았다. Seong 등은 RBD 환자의 긍정적수면상태오인(positive sleep state misperception)에 의한 가능성을 제시한 바 있다. ${ }^{22} \mathrm{RBD}$ 환자는 꿈을 자주 꾼 다고 호소하며, 수면다원검사에서 각성지수 증가, N3 수면 감소 및 수면무호흡지수 증가 등 객관적인 수면의 질 저하 가 뚜렷하게 관찰되지만, 불면증이나 수면 자체에 대한 호소 는 적다는 것이다.22 $\mathrm{OSA}$ 환자에서도 호흡사건의 중증도와 주관적 수면의 질 사이 뚜렷한 연관성을 보이지 않는다. ${ }^{23}$ 이 주제에 관한 후속연구가 필요하다.

본 연구의 제한점은 후향적 연구이며, 표본의 수가 적고, 일개 대학병원에서 진료 및 진단을 내렸기 때문에 선택치우 침의 문제가 있을 수 있다는 것이다. 또한 단순한 질문을 통 해 신체손상의 병력 여부를 확인하였을 뿐, 신체손상의 정도 나 빈도에 대한 고려는 하지 않았다. RBD의 중증도는 폭력 의 정도와 빈도 및 신체손상의 위험으로 구분할 수 있다. 그 러나 빈도는 환자나 배우자가 수면 중 발생하는 움직임을 인 지하는 능력에 따라 좌우된다. ${ }^{14}$ 따라서 개개인의 차이에 따 른 영향이 적은 신체 손상의 여부만을 고려하였으나, 여전히 회상치우침의 가능성을 배제할 수 없다.

결론적으로 $\mathrm{RBD}$ 환자의 수면 중 신체손상은 OSA와 연 관이 있다. 따라서 $\mathrm{RBD}$ 가 의심되는 환자에게서 신체손상의 병력이 있다면, OSA 환자가 보이는 일반적인 특징인 비만과 코골이가 $\mathrm{RBD}$ 에게서는 뚜렷하지 않다는 점을 고려하여, $\mathrm{OSA}$ 의 동반 가능성을 고려하고, 그 진단을 위해 수면다원 검사를 계획하는 것이 필요하다. 임상에서 $\mathrm{RBD}$ 로 의심되는 
환자를 대할 때 신체손상의 병력을 확인하는 것이 중요하다.

\section{Acknowledgments}

None.

\section{Conflicts of Interest}

The authors have no potential conflicts of interest to disclose.

\section{ORCID iDs}

Ki-Hwan Ji https://orcid.org/0000-0002-5371-5398

Mi-Ri Kang https://orcid.org/0000-0002-9833-023X

\section{Author Contributions}

Conceptualization : Ki-Hwan Ji. Data curation: Ki-Hwan Ji. Formal analysis: Ki-Hwan Ji. Investigation: Mi-Ri Kang, Ki-Hwan Ji. Methodology: Ki-Hwan Ji. Visualization: Ki-Hwan Ji. Writing-original draft: Ki-Hwan Ji. Writing-review \& editing: Mi-Ri Kang, Ki-Hwan Ji.

\section{REFERENCES}

1. Schenck CH, Bundlie SR, Ettinger MG, Mahowald MW. Chronic behavioral disorders of human REM sleep: a new category of parasomnia. Sleep 1986;9:293-308. https://doi.org/10.1093/sleep/9.2.293.

2. Schenck CH, Bundlie SR, Patterson AL, Mahowald MW. Rapid eye movement sleep behavior disorder. A treatable parasomnia affecting older adults. JAMA 1987;257:1786-1789. https://doi.org/10.1001/ jama.1987.03390130104038.

3. Iranzo A, Molinuevo JL, Santamaría J, et al. Rapid-eye-movement sleep behaviour disorder as an early marker for a neurodegenerative disorder: a descriptive study. Lancet Neurol 2006;5:572-577. https://doi. org/10.1016/S1474-4422(06)70476-8.

4. Schenck CH, Mahowald MW. REM sleep behavior disorder: clinical, developmental, and neuroscience perspectives 16 years after its formal identification in SLEEP. Sleep 2002;25:120-138. https://doi.org/10.1093/ sleep/25.2.120.

5. American Academy of Sleep Medicine. International classification of sleep disorders: diagnostic and coding manual. 3rd ed. Darien: American Academy of Sleep Medicine, 2014.

6. Shahar E, Whitney CW, Redline S, et al. Sleep-disordered breathing and cardiovascular disease: cross-sectional results of the Sleep Heart Health Study. Am J Respir Crit Care Med 2001;163:19-25. https://doi. org/10.1164/ajrccm.163.1.2001008.

7. Gabryelska A, Roguski A, Simpson G, Maschauer EL, Morrison I, Riha RL. Prevalence of obstructive sleep apnoea in REM behaviour disorder: response to continuous positive airway pressure therapy. Sleep Breath 2018;22:825-830. https://doi.org/10.1007/s11325-017-1563-9.

8. Olson EJ, Boeve BF, Silber MH. Rapid eye movement sleep behaviour disorder: demographic, clinical and laboratory findings in 93 cases. Brain 2000;123:331-339. https://doi.org/10.1093/brain/123.2.331.
9. Iranzo A, Santamaría J. Severe obstructive sleep apnea/hypopnea mimicking REM sleep behavior disorder. Sleep 2005;28:203-206. https:// doi.org/10.1093/sleep/28.2.203.

10. Johns MW. A new method for measuring daytime sleepiness: the Epworth sleepiness scale. Sleep 1991;14:540-545. https://doi.org/10.1093/ sleep/14.6.540.

11. Beck AT, Ward CH, Mendelson M, Mock J, Erbaugh J. An inventory for measuring depression. Arch Gen Psychiatry 1961;4:561-571. https:// doi.org/10.1001/archpsyc.1961.01710120031004.

12. Bastien $\mathrm{CH}$, Vallières A, Morin CM. Validation of the Insomnia Severity Index as an outcome measure for insomnia research. Sleep Med 2001;2:297-307. https://doi.org/10.1016/s1389-9457(00)00065-4.

13. Iber C, Ancoli-Israel S, Chesson A, Quan SF. The AASM manual for the scoring of sleep and associated events: rules, terminology and technical specifications. Westchester: American Academy of Sleep Medicine, 2007.

14. Arnulf I. REM sleep behavior disorder: motor manifestations and pathophysiology. Mov Disord 2012;27:677-689. https://doi.org/10.1002/ mds.24957.

15. BaHammam AS, Almeneessier AS. Dreams and nightmares in patients with obstructive sleep apnea: a review. Front Neurol 2019;10: 1127. https://doi.org/10.3389/fneur.2019.01127.

16. Pagel JF, Kwiatkowski C. The nightmares of sleep apnea: nightmare frequency declines with increasing apnea hypopnea index. J Clin Sleep Med 2010;6:69-73. https://doi.org/10.5664/jcsm.27713.

17. Hackius M, Werth E, Sürücü O, Baumann CR, Imbach LL. Electrophysiological evidence for alternative motor networks in REM sleep behavior disorder. J Neurosci 2016;36:11795-11800. https://doi.org/10.1523/ JNEUROSCI.2546-16.2016.

18. Tahmasian M, Rosenzweig I, Eickhoff SB, et al. Structural and functional neural adaptations in obstructive sleep apnea: an activation likelihood estimation meta-analysis. Neurosci Biobehav Rev 2016;65:142156. https://doi.org/10.1016/j.neubiorev.2016.03.026.

19. Schuld A, Kraus T, Haack M, Hinze-Selch D, Pollmächer T. Obstructive sleep apnea syndrome induced by clonazepam in a narcoleptic patient with REM-sleep-behavior disorder. J Sleep Res 1999;8:321-322. https://doi.org/10.1046/j.1365-2869.1999.00162.x.

20. Bugalho P, Mendonça M, Barbosa R, Salavisa M. The influence of sleep disordered breathing in REM sleep behavior disorder. Sleep Med 2017; 37:210-215. https://doi.org/10.1016/j.sleep.2017.05.012.

21. Kim KT, Motamedi GK, Cho YW. Quality of life in patients with an idiopathic rapid eye movement sleep behaviour disorder in Korea. $J$ Sleep Res 2017;26:422-427. https://doi.org/10.1111/jsr.12486.

22. Seong MJ, Jung AR, Park HR, Choi SJ, Joo EY. Dream recall frequency and sleep in patients with rapid eye movement sleep behavior disorder. J Sleep Med 2017;14:55-60. https://doi.org/10.13078/jsm.17008.

23. Wu MN, Lai CL, Liu CK, et al. More severe hypoxemia is associated with better subjective sleep quality in obstructive sleep apnea. BMC Pulm Med 2015;15:117. https://doi.org/10.1186/s12890-015-0112-1. 